\title{
CHARACTERIZATION OF TISSUE-DERIVED MACROMOLECULES AFFECTING TRANSMITTER SYNTHESIS IN RAT SPINAL CORD NEURONS ${ }^{1}$
}

\author{
LAWRENCE M. KAUFMAN, ${ }^{2}$ SUSAN R. BARRY, ${ }^{3}$ AND JOHN N. BARRETT ${ }^{4}$ \\ Department of Physiology and Biophysics, University of Miami, Miami, Florida 33101
}

Received March 9, 1984; Accepted June 14, 1984

\begin{abstract}
Rat spinal cord cells maintained in neuron-rich cultures were exposed to extracts of skeletal muscle or to medium conditioned by non-neuronal cells. The conditioned media enhanced neuronal acetylcholine (ACh) synthesis, choline acetyltransferase activity, and protein synthesis, and decreased $\gamma$-aminobutyric acid (GABA) synthesis. Muscle extract prepared from newborn rats produced similar enhancements but did not depress GABA synthesis. Muscle extracts prepared from normal and denervated adult rat limbs contained relatively little activity. These results suggest that different molecular factors might mediate the effects on GABA and ACh synthesis. Gel filtration of conditioned media and muscle extracts revealed that all of these activities were confined to a macromolecular fraction with an apparent $M_{\mathrm{r}}$ of 40,000 . These tissue-derived factors affecting neuronal protein and transmitter synthesis are in turn distinct from a neuronal survival-promoting factor obtained from serum (Kaufman, L. M., and J. N. Barrett (1983) Science 220: 1394-1396).
\end{abstract}

Spinal cord neurons are influenced by interactions with the tissues they innervate. For example, the survival of spinal motoneurons appears to depend on the target muscle tissue: ablating the limbs of fetal animals results in the death of the motoneurons that would normally innervate those limbs (Hamburger, 1934). Czeh et al. (1978) found that muscle activity affects motoneuron electrical properties via a chemical messenger that is retrogradely transported in the motoneuron axon.

Specific soluble molecules that mediate interactions between spinal cord neurons and their target tissues are difficult to characterize in an in vivo system. Tissue culture of spinal cord neurons provides a relatively easy system to assay for such trophic molecules, with the eventual goal of isolating them for in vivo study. These tissue culture studies are facilitated by the recent discovery of a serum fraction which allows long-term survival of neuron-rich cultures (Kaufman and Barrett, 1983).

Previous tissue culture studies have shown that tissue extracts and medium conditioned by non-neuronal cells enhance several properties of mammalian spinal cord neurons, including acetylcholine (ACh) synthesis (Smith and Appel, 1983), choline acetyltransferase (CAT) activity (Giller et al., 1977; Godfrey et

\footnotetext{
${ }^{1}$ We wish to thank Doris Nonner for skillful assistance with the culture system and assays, and Dr. Ellen Barrett for helpful discussions about the manuscript. This work was supported by National Institutes of Health Grants NS12207 and NS07044.

${ }^{2}$ Present address: Department of Ophthalmology, University of Florida, Gainesville, FL 00000.

${ }^{3}$ Present address: Department of Physiology, University of Michigan, 7773 Medical Sciences Building 2, Ann Arbor, MI 48109.

${ }^{4}$ To whom correspondence should be addressed, at the Department of Physiology and Biophysics, University of Miami, P. O. Box 016430, Miami, FL 33101.
}

al., 1980; Smith and Appel, 1983), and neurite outgrowth (Henderson et al., 1981; Dribin and Barrett, 1980, 1982; Tanaka et al., 1982; Nurcombe et al., 1984). Attempts at characterizing and isolating the trophic substances underlying these effects have revealed that several distinct macromolecules are involved. For example, the ability of conditioned medium to promote neurite outgrowth is mediated by at least two synergistic macromolecules (Longo et al., 1982), one with an apparent $M_{\mathrm{r}}>200,000$ that binds to the tissue culture substrate, the other with an $M_{\mathrm{r}}$ of 50,000 that does not act via long-term binding to the substrate (Dribin and Barrett, 1982). Substratebinding molecules have also been shown to enhance the growth of neurites from ciliary ganglion ncurons and sympathetic ganglion neurons (Collins, 1978; Lander et al., 1982). We report here studies designed to characterize the tissue-derived macromolecules that alter synthesis of protein and neurotransmitters $\mathrm{ACh}$ and $\gamma$-aminobutyric acid (GABA) in rat spinal cord neurons.

\section{Materials and Methods}

Cell culture. Monolayer cultures of dissociated neurons were prepared from spinal cords dissected from fetal Sprague-Dawley rats at 14 days gestation. All of the cords from a single litter were combined in $5 \mathrm{ml}$ of phosphate-buffered saline. The tissue was mechanically dissociated by pipetting about 30 times through a $2-\mathrm{mm}$ tip bore plastic pipette. Cell clumps were allowed to settle for $4 \mathrm{~min}$. The supernatants from three serial pipettings performed on successive cell pellets were combined and diluted into a larger volume of a cerebrospinal fluid (CSF)-like, defined nutrient medium (Kaufman and Barrett, 1983). The cell suspension was pipetted into 16 -mm-diameter tissue culture wells (Costar), at a final plating density of about 550 viable cells $/ \mathrm{mm}^{2}$. Culture wells were coated prior to plating with a thin, air-dried layer of acidsoluble rat-tail collagen, followed by a 30-min exposure to a solution of $10 \mu \mathrm{g}$ of poly-L-lysine/ml (Sigma, type 1-B, buffered to $\mathrm{pH} 9.0$ with 20 $\mathrm{mM}$ bicarbonate). 
All neuronal cultures were maintained in the CSF-like nutrient medium supplemented with a neuronal survival-promoting factor obtained from gel filtration (at $\mathrm{pH} 3.6$ ) of horse serum (Kaufman and Barrett, 1983). The neuronal survival-promoting factor was used at a final concentration of 10 biological units $(\mathrm{BU}) / \mathrm{ml}$ of nutrient medium, a concentration yielding maximal neuronal survival. Because this serum fraction does not support proliferation of non-neuronal cells, spinal cord cultures remained neuron-rich for months. Typically, after 2 weeks in culture, at least $90 \%$ of the cells in these spinal cord cultures were neurons, with a density of about $500 \pm 50$ neurons $/ \mathrm{mm}^{2}$. Neuronal and non-neuronal cells were distinguished by their morphology (neurons have phase-bright, rounded cell bodies with long processes). Neuronal survival was assessed by averaging neuron counts from at least 15 microscopic fields in four separate culture wells.

Samples of muscle extract or conditioned medium to be bioassayed for trophic activity were equilibrated in the CSF-like nutrient medium and added to the spinal cord cultures $2 \mathrm{hr}$ postplating. Control cultures were diluted with an equal volume of unsupplemented CSF-like medium. Note that all neuronal cultures were originally plated in CSFlike medium containing neuronal survival-promoting factor at a concentration of $20 \mathrm{BU} / \mathrm{ml}$. The level of the survival factor in both experimental and control cultures was then diluted to $10 \mathrm{BU} / \mathrm{ml}$ by the addition of experimental or control samples. Cultures were re-fed at day 5 postplating and assayed between days 8 and 12 . Figure 1 shows photomicrographs of control and experimental spinal cord cultures at 12 days in vitro.

Conditioned medium and muscle extract. Medium conditioned by exposure to cultures of rat skeletal muscle or lung was prepared as described by Dribin and Barrett (1980). Briefly, limb skeletal muscle or lung from day-20 fetal Sprague-Dawley rats was dissociated and plated into tissue culture dishes. The cultures were maintained for 1 week in Dulbecco's modified Eagle's medium (DMEM) supplemented with $10 \%$ horse serum. Cultures were then washed with serum-free DMEM (three 10-min washes) and incubated in fresh serum-free DMEM for an additional 3 days. About $150 \mathrm{ml}$ of this conditioned medium were then collected, concentrated to $1 \mathrm{ml}$ by ultrafiltration (PTGC, Millipore, 10,000 $M_{\mathrm{r}}$ cutoff), and either directly bioassayed (after dilution to $20 \mathrm{ml}$ with fresh CSF-like medium) or subjected to gel filtration prior to bioassay.

Muscle extract was prepared from limb skeletal muscle of both newborn and adult Sprague-Dawley rats. Muscle from adult rats was obtained from the gastrocnemius and soleus muscles of normal rats and from rats in which the hindlimbs were denervated 5 days previously by transection of the sciatic nerve at hip level. Dissected muscle was diluted 1:2(w/v) in an ice-cold solution containing $250 \mathrm{~mm}$ sucrose and $0.5 \mathrm{~mm}$ EDTA at $\mathrm{pH}$ 7.4. The tissue was minced, homogenized in a glass-on-glass tissue grinder, and centrifuged at $10,000 \times \mathrm{g}$ for $1 \mathrm{hr}$. The supernatant was then recentrifuged at $100,000 \times g$ for $1 \mathrm{hr}$. Onemilliliter aliquots of the second supernatant were gel filtered prior to bioassay.

Growth assays. Two indices were used to assess growth of spinal cord neurons in culture; protein synthesis and lactate dehydrogenase (LDH) activity.

The rate of protein synthesis was determined by measuring the ability of cultured cells to incorporate radioactive amino acids into trichloroacetic acid (TCA)-precipitable protein (Nishi and Berg, 1981). Briefly, spinal cord cultures were incubated for $4 \mathrm{hr}$ in CSF-like medium containing a 1:150 dilution of a ${ }^{3} \mathrm{H}$-amino acid mixture (Amersham, TRK. $550 ; 1 \mathrm{mCi} / \mathrm{ml}$ ). Cultures were then washed with fresh CSF-like medium and homogenized in $0.3 \mathrm{ml}$ of $10 \%$ TCA. After $12 \mathrm{hr}$ at $4^{\circ} \mathrm{C}$, the protein precipitate was pelleted at $10,000 \times \mathrm{g}$ for $10 \mathrm{~min}$. This pellet was rinsed with $0.1 \mathrm{ml}$ of $10 \%$ TCA and dissolved in $0.6 \mathrm{M} \mathrm{NaOH}$ $(150 \mu \mathrm{l})$, and a $75-\mu \mathrm{l}$ aliquot was then measured for radioactivity (in 4 $\mathrm{ml}$ of Aquasol 2, New England Nuclear) on a Packard scintillation spectrometer.

$\mathrm{LDH}$, a ubiquitous cytoplasmic enzyme important in the glycolytic pathway, has been used as a marker to assess overall cell growth (Nishi and Berg, 1981). Samples for measurement of LDH activity were prepared by homogenizing cultured cells in $0.1 \mathrm{ml}$ of buffer containing $5 \mathrm{~mm}$ phosphate, $10 \mathrm{mM}$ EDTA, $0.5 \%$ Triton X-100, and $5 \mathrm{mg}$ of bovine serum albumin/ml, at $\mathrm{pH} 7.4$. LDH activity in a $50-\mu \mathrm{l}$ aliquot was determined by spectrophotometrically following the oxidation of NADH (at $340 \mathrm{~nm}$ ) during the LDH-catalyzed reduction of pyruvate to lactate (Sigma kit no. 340-UV; Wroblewski and LaDue, 1955). One unit of LDH activity represents a decrease of 0.001 absorbance units/ $\min$.

CAT. CAT activity was chemically assayed using the method of Fonnum (1975). The procedure measures the incorporation of isotope into ACh during the CAT-catalyzed synthesis of $\mathrm{ACh}$ from radiolabeled acetylcoenzyme A and choline. Aliquots of cell homogenates, prepared as described above for $\mathrm{LDH}$ activity, were incubated for $30 \mathrm{~min}$ at $37^{\circ} \mathrm{C}$ with a solution containing choline chloride and $\left[1{ }^{14} \mathrm{C}\right]$ acetylcoenzyme A diluted to 50,000 to $75,000 \mathrm{dpm}$ (Amersham; specific activity, 51.6 $\mathrm{mCi} / \mathrm{mmol}$. ACh was specifically extracted from the aqueous reaction mixture into an organic phase (containing the scintillation chemicals) by the addition of tetraphenylboron dissolved in acetonitrile. The extraction was essentially $100 \%$ efficient when performed with $\left[1-{ }^{14} \mathrm{C}\right]$ acetylcholine chloride (Amersham). Background counts were less than
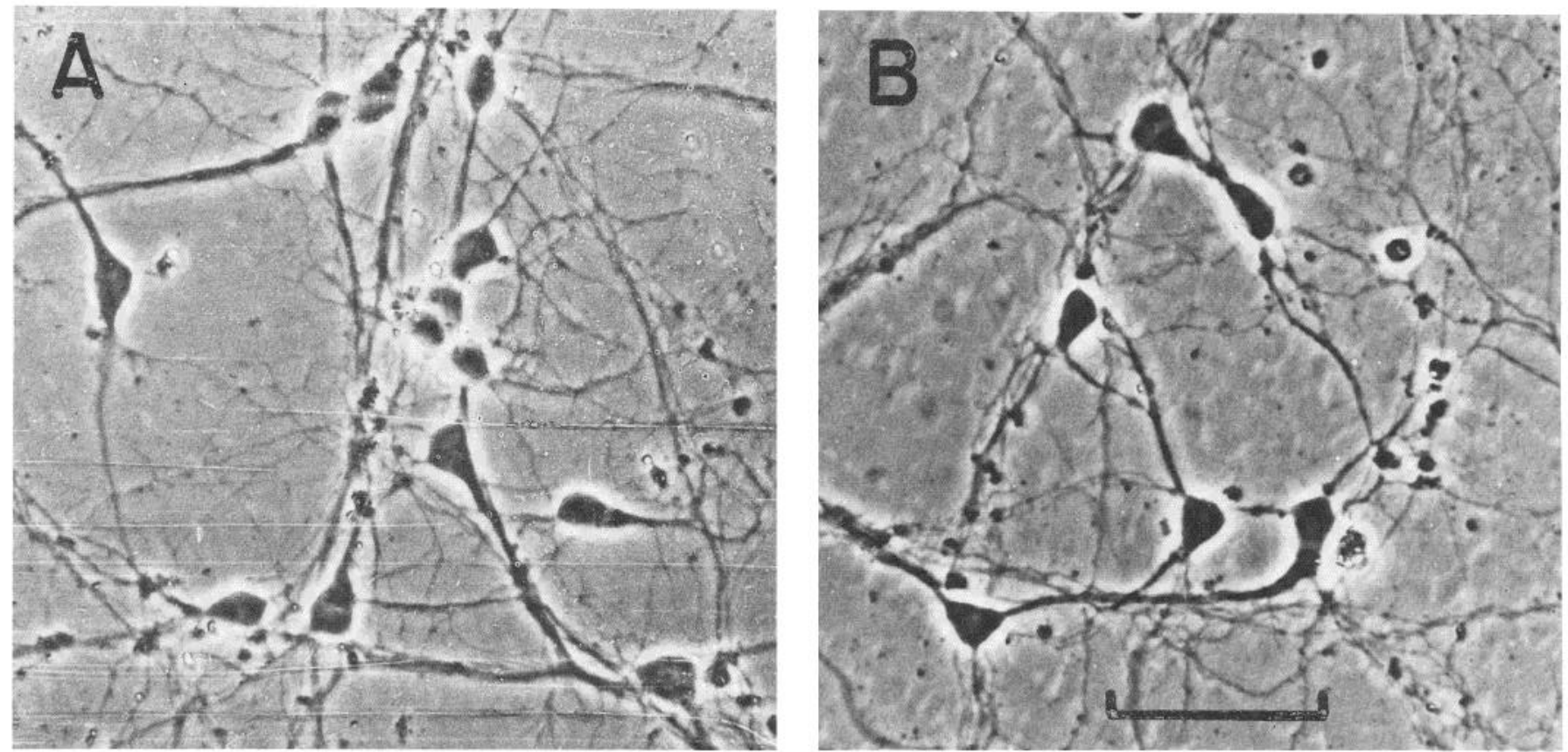

Figure 1. Photomicrographs of rat spinal cord neurons in a control culture $(A)$ and an experimental culture $(B)$ that was supplemented with the active gel filtration fraction of MCM (see "Materials and Methods" and Fig. 2), at 12 days postplating. Calibration bar, $50 \mu \mathrm{m}$. 
$1 \%$ of the starting $\left[1^{14} \mathrm{C}\right]$ acetylcoenzyme A counts. Following cell homogenate incubations, $\mathrm{ACh}$ counts ranged from 100 to $2000 \mathrm{cpm}$ above background. Moles of ACh synthesized were derived from the scintillation counts, using the specific activity of the radiolabel and counting efficiency $(80.9 \%)$.

Since enzymes such as carnitine acetyltransferase might contribute to the activity measured in the Fonnum (1975) assay for CAT, we performed several tests to check the specificity of this assay in our culture system. Addition of acetylcholinesterase in place of neostigmine in the incubation medium reduced the net synthesis of ACh to less than $5 \%$ of paired samples not treated with the esterase. Naphthylvinyl pyridine $(1 \mathrm{~mm})$, a specific inhibitor of CAT activity (White and Cavallito, 1970), caused a 97\% reduction in ACh synthesis compared to untreated pairs. Cultures of cerebellum, lung fibroblasts, or myotubes with cell densities similar to those of the spinal cord cultures had less than $10 \%$ of the CAT activity measured in even the control spinal cord cultures. Thus, the activity measured by the Fonnum (1975) assay in our system appears to the specific for CAT without significant contamination from other enzymes.

Neurotransmitter synthesis. Synthesis of ACh and GABA by neurons in culture were determined after incubations with radiolabeled precursors (Berg, 1978). Cells were incubated for $4 \mathrm{hr}$ in CSF-like medium containing $\left[\right.$ methyl $\left.{ }^{3} \mathrm{H}\right]$ choline chloride (Amersham; specific activity, $15 \mathrm{Ci} / \mathrm{mmol}$; diluted with unlabeled choline to a final specific activity of $0.52 \mathrm{Ci} / \mathrm{mmol}$ ) or $\left[\mathrm{L}-2,3-{ }^{3} \mathrm{H}\right]$ glutamic acid (New England Nuclear; specific activity, $21.6 \mathrm{Ci} / \mathrm{mmol}$ ). After incubation, cells were washed and homogenized, and aliquots of the homogenate measured for radioactivity incorporated into $\mathrm{ACh}$ or GABA. The neurotransmitters were separated from precursors and by-products by high voltage paper electrophoresis (Hildebrand et al., 1971). Overall counting efficiency was $28.4 \%$.

Gel filtration. High performance liquid chromatography (HPLC) was performed on a $7.5 \times 600 \mathrm{~mm}$ prepacked column (TSK G3000 SW, Toyo Soda). The gel was pre-equilibrated in a pH 7.0 buffer solution containing $10 \mathrm{mM}$ phosphate and $150 \mathrm{mM} \mathrm{NaCl}$. A $1-\mathrm{ml}$ sample was loaded onto the gel and eluted against gravity at a flow rate of $2 \mathrm{ml} /$ $\mathrm{hr}$. Eluted fractions were diluted to $20 \mathrm{ml}$ with CSF-like medium, for bioassay. The effective fractionation range of this gel column for globular proteins is 5,000 to 150,000 daltons.

Isoelectric focusing. Preparative isoelectric focusing was performed using a granulated gel (Ultrodex, LKB) in a $25 \times 1.0 \times 0.4 \mathrm{~cm}$ flat bed. The gel was wetted with diluted Ampholine solution (LKB, pH 3 to 10 ), and air-dried on the bed. The final concentration of Ampholines in the gel was $2 \%$. The anode and cathode wicks were wetted with a solution of $1 \mathrm{M}$ phosphoric acid and $1 \mathrm{M} \mathrm{NaOH}$, respectively. After a 1 -hr prefocus period, a 1-ml sample was applied to the gel. Focusing was performed for 12 to $14 \mathrm{hr}$ at $2 \mathrm{~W}$ constant power. After focusing, the gel was divided into equal fractions, and the $\mathrm{pH}$ of each was measured. The fractions were then neutralized and eluted from the granulated gel with $20 \mathrm{ml}$ of CSF-like medium, for bioassay.

Protein assay. Protein concentration was measured using the method of Bradford (1976). Reagents were from Bio-Rad Laboratories, and bovine serum albumin was used as the standard.

Statistics. The Student's $t$ test (two-tailed) was used to determine statistical significance when comparing one experimental group to a control. When more than one group was simultaneously compared to a single control, a one-way analysis of variance was performed. Dunnett's test for multiple comparisons (two-tailed) was then used to determine which treatments yielded results significantly different from control.

\section{Results}

Table I documents the neuronal response to medium conditioned by rat skeletal muscle cultures. Muscle conditioned medium (MCM), prepared as described under "Materials and Methods," was applied to spinal cord neuronal cultures at a final concentration of about $250 \mu \mathrm{g}$ of protein $/ \mathrm{ml}$ of medium. The neuronal cultures exposed to the MCM displayed increased rates of synthesis for $\mathrm{ACh}$ and total protein, as well as increased CAT and LDH activity. Synthesis of GABA in the MCMtreated cultures was reduced to $50 \%$ of control. As a control, we also performed these chemical assays directly on MCM and found that MCM contained up to 4 times the LDH activity measured in homogenates of neuronal cultures exposed to
MCM. Thus, the increase in LDH activity in MCM-treated cultures cannot be safely attributed to an increase in neuronal LDH (see also Fig. 4). The other chemical assays yielded blank values when performed directly on MCM. Treatment with MCM did not affect the number of surviving neurons or nonneuronal cells. The finding that MCM enhances cholinergic properties (CAT activity and $\mathrm{ACh}$ synthesis) but decreases GABA synthesis is reminiscent of the finding by Giller et al. (1977) that co-culture of spinal cord neurons with muscle cells increases CAT activity while decreasing the activity of glutamic acid decarboxylase, the final enzyme in GABA synthesis.

Gel filtration of MCM on an HPLC column was performed to determine the molecular weight of the molecule(s) underlying these effects of MCM on neurons. Fractions of the column eluate were applied to spinal cord neuronal cultures for bioassay. After 8 to 12 days these cultures were chemically assayed for synthesis of ACh, GABA, and protein, and for CAT and $\mathrm{LDH}$ activity. Results of these experiments are shown in Figure 2. The measured parameters were altered only by MCM components eluting at an $M_{\mathrm{r}}$ of $\sim 40,000$. Two cholinergic properties, ACh synthesis (Fig. 2A) and CAT activity (Fig. $2 D$ ), were both significantly enhanced by factors in this molecular weight region, whereas GABA synthesis (Fig. $2 B$ ) was significantly depressed. Total protein synthesis (Fig. $2 C$ ) and LDH activity (Fig. $2 E$ ) were similarly increased significantly by the $M_{\mathrm{r}}=$ 40,000 fractions. Cell counts indicated that none of the fractions had an effect on the number of neuronal or non-neuronal cells surviving during the bioassay period.

Effects of gel-filtered MCM fractions on CAT activity in cultured spinal cord neurons were measured in nine separate experiments like that in Figure $2 A$. Five of these experiments gave similar results, namely, a maximal and statistically significant $(p<0.05)$ stimulation of CAT activity at $M_{\mathrm{r}}=40,000$. In these five experiments, recovery of biological activity after gel filtration ranged from 20 to $100 \%$. Twice, no detectable CAT-stimulating activity was recovered from the column. Twice, significant activity was found in lower molecular weight fractions, once at 13,000 daltons, and once at 7,000 daltons. The elution of CAT-stimulating activity at a lower molecular weight in these latter experiments might reflect proteolytic digestion of a trophic factor with preservation of activity or dissociation of a larger complex that released a smaller active subunit.

Effects of gel-filtered MCM fractions on ACh, GABA, and protein synthesis, and on $\mathrm{LDH}$ activity were measured in two additional experiments both of which yielded data similar to those plotted in Figure 2.

Various dilutions of the active $M_{\mathrm{r}}=40,000 \mathrm{MCM}$ fraction were also bioassayed for their effects on neuronal protein synthesis, CAT activity, and GABA synthesis (Fig. 3). Both protein synthesis and CAT activity increased with increasing concentration of the active $\mathrm{MCM}$ fraction, whereas GABA synthesis decreased with increasing concentration. The decrease in the synthesis of GABA produced by the $M_{\mathrm{r}}=40,000$ MCM fraction saturated at the intermediate dilution $(50 \mu \mathrm{g}$ of protein $/ \mathrm{ml}$ ).

Macromolecules from other sources were also bioassayed for their effects on spinal cord neuronal cultures. Sources included lung conditioned medium (LCM) and extracts prepared from newborn, normal adult, and adult denervated rat skeletal muscle (see "Materials and Methods"). LCM and muscle extracts were gel filtered on the same HPLC column as that used for MCM, and all of the eluted fractions were bioassayed for effects on GABA synthesis, protein synthesis, and CAT activity. Again, maximal stimulation of CAT activity and protein synthesis, and suppression of GABA synthesis were found to reside in fractions eluting at an $M_{\mathrm{r}}$ near 40,000 .

Figure 4 demonstrates the relative effectiveness of the $M_{\mathrm{r}}=$ 
TABLE I

Influence of $M C M$ on neuronal development

Spinal cord cultures were prepared with CSF-like nutrient medium containing the serum-derived neuronal survival-promoting factor at an initial concentration of $20 \mathrm{BU} / \mathrm{ml}$. Medium in the wells was then diluted by half with either unsupplemented CSF-like medium (control) or MCM (equilibrated by ultrafiltration into the CSF-like medium). At 8 to 12 days postplating, cultures were assayed for rates of synthesis of ACh, GABA, and protein, and for CAT and LDH activity. Values represent the means \pm SD for the specified number of culture dishes.

\begin{tabular}{|c|c|c|c|c|c|}
\hline & $\begin{array}{c}\mathrm{ACh} \\
(\mathrm{pmol} / \mathrm{hr} / \text { culture })\end{array}$ & $\begin{array}{c}\text { GABA } \\
\text { (fmol/hr/culture) }\end{array}$ & $\begin{array}{c}\text { Protein } \\
\text { (cpm/culture) }\end{array}$ & $\begin{array}{c}\mathrm{CAT} \\
\text { (pmol of ACh/min/culture) }\end{array}$ & $\begin{array}{c}\text { LDH } \\
\text { (units/culture) }\end{array}$ \\
\hline $\begin{array}{l}\text { Control } \\
(n)\end{array}$ & $\begin{array}{c}1.24 \pm 0.03 \\
(3)\end{array}$ & $\begin{array}{c}430 \pm 7 \\
(2)\end{array}$ & $\begin{array}{c}5119 \pm 2245 \\
(3)\end{array}$ & $\begin{array}{c}2.5 \pm 0.4 \\
(5)\end{array}$ & $\begin{array}{c}22.3 \pm 1.2 \\
(3)\end{array}$ \\
\hline
\end{tabular}

${ }^{a} p<0.05$.

${ }^{b} p<0.01$.

40,000 fraction from these various sources. The fraction from LCM was the most potent for all of the activities; however, spinal cord cultures exposed to the $M_{\mathrm{r}}=40,000$ fraction from LCM had up to a 4-fold increase above control in total number of non-neuronal cells. Proliferation of non-neuronal cells was not evident in spinal cord cultures maintained in active fractions derived from MCM or any of the muscle extracts. None of the fractions altered neuronal survival as measured by our cell counts. Normal adult (AMX) and denervated adult (DMX) muscle extract contained relatively little activity. Newborn muscle extract (NMX) caused an increase in protein synthesis and CAT activity but did not depress GABA synthesis.

The tissue-derived factors that enhance neuronal protein synthesis and CAT activity and depress GABA synthesis are not present in appreciable amounts in the acid gel filtration fraction of horse serum used here to support neuronal survival. The spinal cord cultures were routinely maintained in nutrient medium supplemented with $10 \mathrm{BU} / \mathrm{ml}$ of this serum fraction. Doubling the concentration of the serum fraction did not produce a statistically significant change in GABA synthesis, protein synthesis, CAT activity (Fig. 4), or in the number of surviving neurons.

As described above, the MCM-produced increase in $\mathrm{LDH}$ activity in neuronal cultures may be an artifact due to the presence of $\mathrm{LDH}$ in the MCM, rather than a result of MCM actions on the cultured neurons. The $M_{\mathrm{r}}=40,000$ HPLC fractions from MCM, LCM, and the muscle extracts, when directly chemically assayed, also contained high LDH activity, as did neuronal cultures maintained in medium supplemented with these fractions. Figure 5 compares the profile of LDH activity in fractions of NMX, after isoelectric focusing (Fig. $5 A$ ), with the profile of $\mathrm{LDH}$ activity seen in homogenates of neuronal cultures that had been been maintained in medium supplemented with the isofocused fractions of the NMX (Fig. $5 B)$. Both profiles show a peak at $\mathrm{pH} 9$. Thus, levels of $\mathrm{LDH}$ activity in many of the experimental neuronal homogenates were probably determined in part by the LDH activity in the applied fractions, even though the cultures were washed thoroughly before the LDH assay.

\section{Discussion}

The studies reported here represent initial attempts to characterize macromolecules in conditioned media and muscle extracts that alter transmitter synthesis in cultured rat spinal cord neurons. We have shown that the ability of certain conditioned media and muscle extracts to increase $\mathrm{ACh}$ and protein synthesis and CAT activity, and to decrease GABA synthesis, can be reproduced by a macromolecular fraction whose profile of elution following gel filtration suggests an $M_{\mathrm{r}}$ of $\sim 40,000$. Most of the following discussion concerns two main issues: how these trophic macromolecules might exert their effects, and the separability of the various trophic activities studied here and elsewhere.

Possible mechanisms of action of trophic macromolecules. The present study demonstrates that trophic factors can influence spinal cord neuronal development in the absence of dense populations of non-neuronal cells, and without the antimetabolic drugs usually used to limit proliferation of non-neuronal cells. In previous studies of trophic effects on spinal cord neurons, cells were routinely maintained in medium supplemented with unfractionated serum (Giller et al., 1977; Dribin and Barrett, 1980; Godfrey et al., 1980; Vaca and Smith, 1981; Smith and Appel, 1983). Since whole serum stimulates proliferation of non-neuronal cells, antimetabolic drugs were used to prevent the nondividing neurons from being overgrown by glia and fibroblasts. Vaca and Smith (1981) noted that muscle extract produced a greater enhancement of ACh synthesis in rat spinal cord cultures treated with the metabolic inhibitor fluorodeoxyuridine (FUDR) than in cultures not exposed to FUDR. Our studies, in which neurons were maintained in a serum fraction that does not support proliferation of nonneuronal cells (Kaufman and Barrett, 1983), show that metabolic inhibitors are not required for trophic factor expression. It has been proposed that trophic factors exert their effects on neurons via a primary action on non-neuronal cells. We cannot resolve this issue, but since our cultures contained less than $10 \%$ non-neuronal cells, our results do indicate that the trophic effects studied here do not require dense populations of nonneuronal cells.

Macromolecules derived from conditioned media might alter transmitter synthesis either by affecting the survival of neurons, or by inducing changes in neurons whose survival is otherwise assured. We favor this latter hypothesis since no statistically significant differences in neuronal survival were observed between control and treatment cultures. However, it remains possible that the trophic macromolecules that increases cholinergic properties and protein synthesis may act by increasing the survival of a numerically small subset of neurons that, without any further inductive signal, synthesize neurotransmitter and/or protein. By similar reasoning, the decrease in GABA synthesis may reflect the selective death of a small number of GABAergic neurons.

The hypothesis that the trophic factors might act by inducing specific changes in neuronal transmitter synthesis rather than by controlling survival of neuron subpopulations is attractive since such inductive effects have been found in sympathetic ganglion neurons. In cultures relatively free of non-neuronal cells, these peripheral adrenergic neurons can be induced to reduce their synthesis of norepinephrine and to synthesize $\mathrm{ACh}$ by early exposure to medium conditioned by non-neuronal cells (Patterson et al., 1975; Patterson and Chun, 1977a, b). This plasticity of neurotransmitter synthesis has been demonstrated at the single neuron level (Reichardt and Patterson, 1977). 


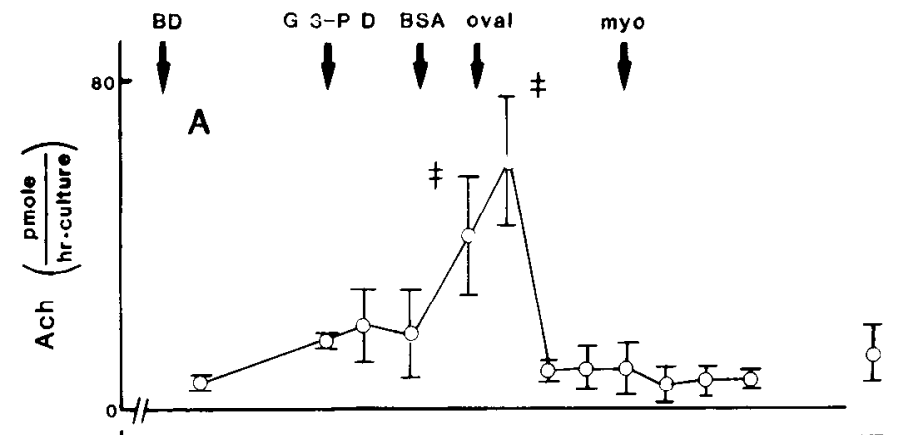

It is tempting to draw parallels between the inverse changes in $\mathrm{ACh}$ synthesis and GABA synthesis produced in spinal cord neurons by conditioned medium (Fig. 2), and the inverse changes in norepinephrine synthesis and ACh synthesis in sympathetic ganglion neurons. However, this comparison is premature because the spinal cord contains a diverse population of neurons as compared to the sympathetic ganglia, raising the possibility that the enhancement of ACh synthesis and the decrease in GABA synthesis occur in separate populations of
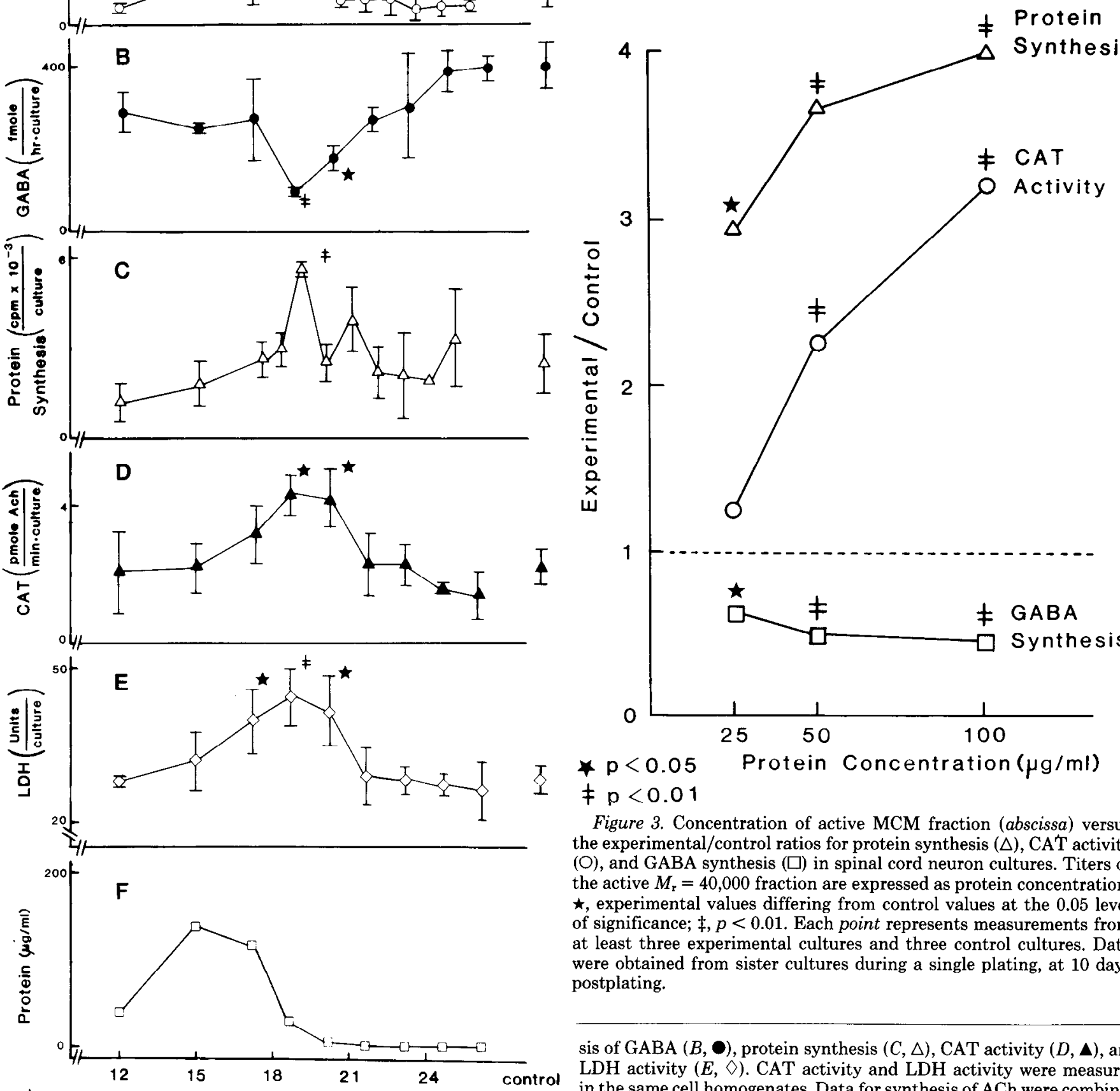

t $p<0.05$

$\neq \mathrm{p}<0.01$

Elution Volume (ml)

Figure 2. Elution profiles of biological activities in MCM. Concentrated MCM was run at $2 \mathrm{ml} / \mathrm{hr}$ through an HPLC column with neutral buffered physiological saline. Eluted fractions were directly diluted into CSF'-like medium and applied to spinal cord neuronal cultures. Control cultures (extreme right, abscissa) received an equal volume of unsupplemented CSF-like medium. All wells contained the neuronal survivalpromoting fraction of horse serum at $10 \mathrm{BU} / \mathrm{ml}$. At 8 to 12 days postplating, cultures were assayed for synthesis of $\mathrm{ACh}(A, O)$, synthe-

Figure 3. Concentration of active MCM fraction (abscissa) versus the experimental/control ratios for protein synthesis $(\triangle)$, CAT activity $(O)$, and GABA synthesis $(\square)$ in spinal cord neuron cultures. Titers of the active $M_{\mathrm{r}}=40,000$ fraction are expressed as protein concentration. $\star$, experimental values differing from control values at the 0.05 level of significance; $\ddagger, p<0.01$. Each point represents measurements from at least three experimental cultures and three control cultures. Data were obtained from sister cultures during a single plating, at 10 days postplating.

sis of GABA $(B, \bullet)$, protein synthesis $(C, \triangle)$, CAT activity $(D, \Delta)$, and LDH activity $(E, \diamond)$. CAT activity and LDH activity were measured in the same cell homogenates. Data for synthesis of ACh were combined from two experiments. The other plots each represent data from an individual experiment. Each point represents the mean value from a minimum of three different culture wells. Vertical bars represent \pm 1 SD. Protein concentrations $(F, \square)$ in fractions of MCM eluted from the column were measured after dilution with nutrient medium, during the experiment for CAT and LDH activity. Arrows at the top indicate elution positions of standards: blue dextran $(B D, 2,000,000)$, glyceraldehyde triphosphate dehydrogenase $(G 3-P D, 140,000)$, bovine serum albumin ( $B S A, 67,000)$, ovalbumin (oval, 40,000), and myoglobin (myo, $17,000)$. The $p$ values were calculated by comparison to controls. 

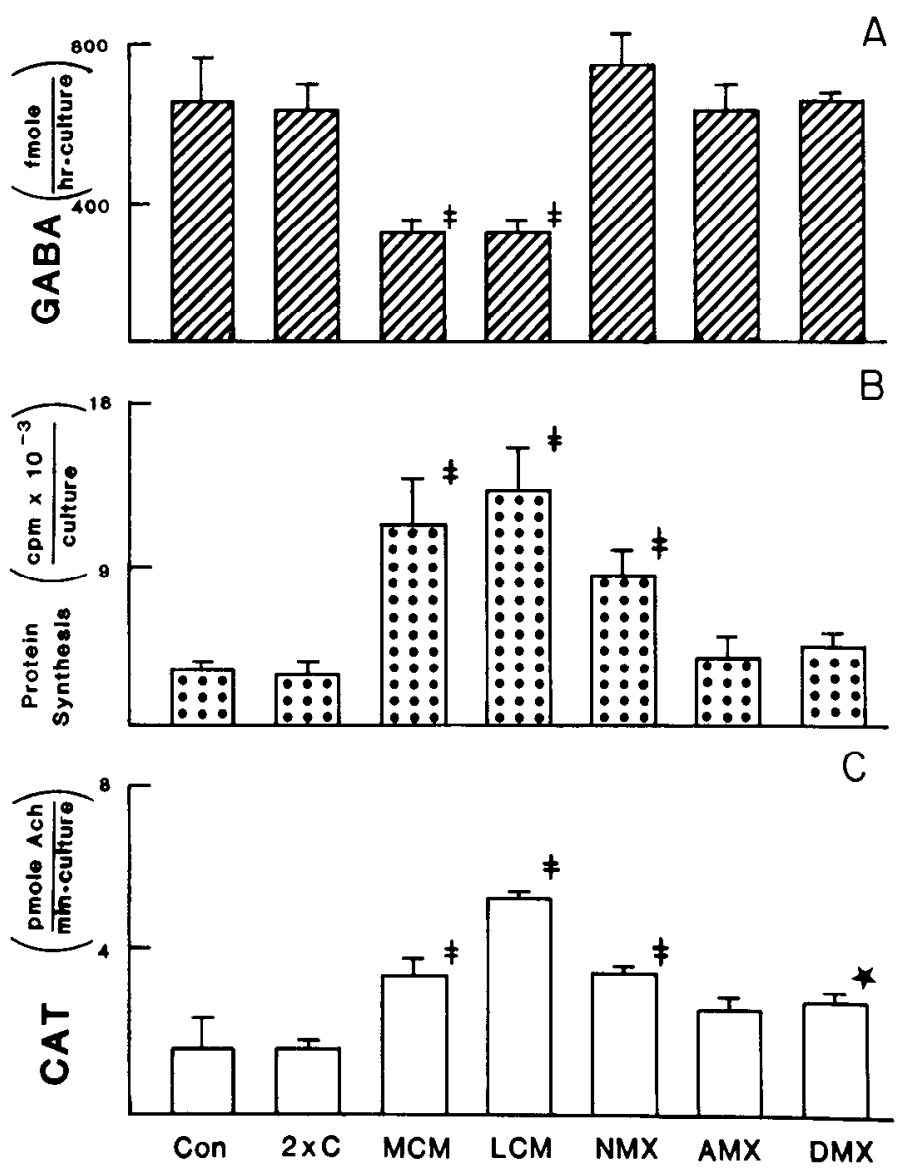

$* 0<0.08$
$\mp D<0.01$

Figure 4. Comparison of the effects of various tissue extracts and conditioned media on GABA synthesis, protein synthesis, and CAT activity in spinal cord neuronal cultures. Medium was conditioned over muscle $(M C M)$ or lung $(L C M)$ cultures, and muscle extract was prepared from newborn $(N M X)$, normal adult $(A M X)$, or denervated adult rat $(D M X)$, as described in the text. Samples were run on the HPLC column, and fractions eluted around $M_{\mathrm{r}}=40,000$ were added to spinal cord neuronal cultures. Control cultures (Con) received an equal volume of CSF-like medium. All cultures were supplemented with serum-derived neuronal survival-promoting factor at $10 \mathrm{BU} / \mathrm{ml}$, except for a second set of control cultures that were supplemented with $20 \mathrm{BU}$ of neuronal survival-promoting factor $/ \mathrm{ml}(2 \times C)$. At 8 to 12 days postplating, cultures were assayed for rates of synthesis of GABA $(A)$ and protein $(B)$, and for CAT activity $(C)$. Values represent the means from three wells. Vertical bars represent 1 SD. Fractions derived from muscle extracts were applied to cultures at the same final dilution (w/ v). Fractions derived from conditioned media were applied at the same final concentration $(\mathrm{v} / \mathrm{v})$. All data were obtained from sister cultures during a single plating.

neurons. Nonetheless, it remains an attractive theory that the early spinal cord contains a precursor set of neurons that is plastic with regard to transmitter synthesis (Le Douarin, 1981), with the ability to become either cholinergic or GABAergic neurons as directed by environmental factors. This would be an economical developmental strategy, since one precursor pool could give rise to diverse populations of neurons whose ultimate transmitter choice was specified by trophic signals from inputs or targets.

Another possibility compatible with our data is that a set of neurons already determined with respect to transmitter synthesis and survival might display increased transmitter synthesis in response to a trophic factor that nonspecifically stimulates overall cell growth and/or metabolism.

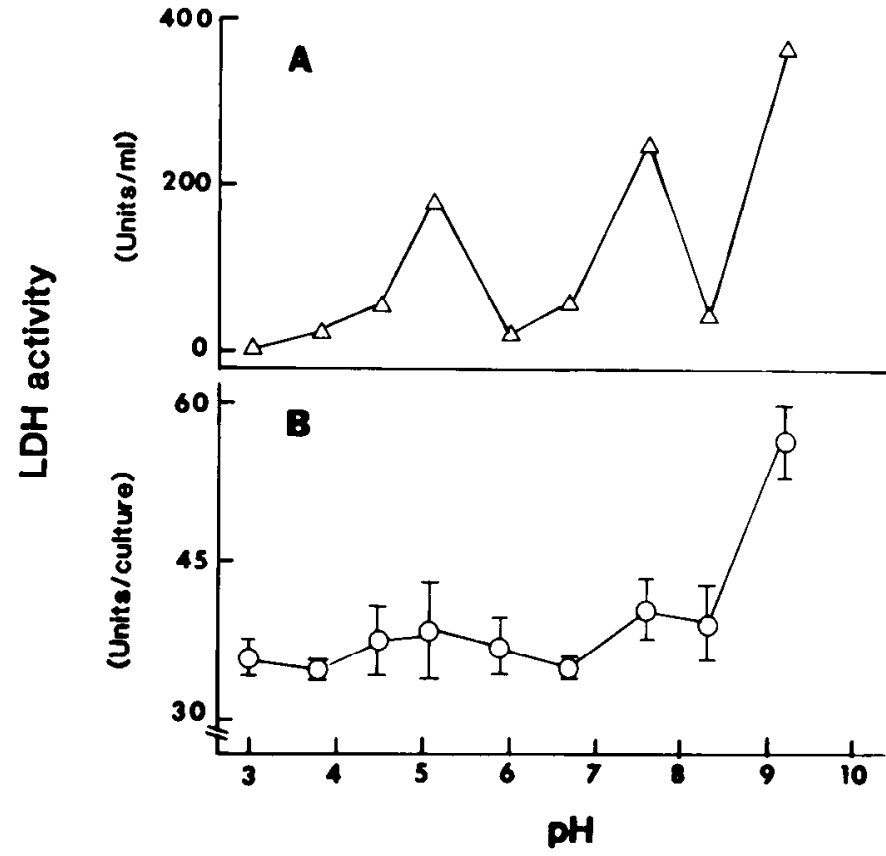

Figure 5. A, Profile of LDH activity in fractions of NMX following isoelectric focusing. $B$, Profile of $\mathrm{LDH}$ activity in homogenates of spinal cord neurons maintained in these isofocused fractions. Focused fractions were neutralized and diluted in CSF-like medium, before being added to neuronal cultures. Values are the means from three cultures, and vertical bars represent $\pm 1 \mathrm{SD}$.

How many trophic macromolecules affect spinal cord neurons? Recent demonstrations that survival and several aspects of the development of spinal cord neurons in culture are significantly influenced by soluble factors raise the question of how many different molecules underlie these trophic effects. In the present study, survival of neurons in both control and experimental cultures was supported by a nutrient medium supplemented with a serum-derived factor. This serum factor appears to be distinct from the tissue-derived factors we describe that influence spinal cord neuronal growth and transmitter synthesis. Doubling the concentration of the serum-derived, neuronal survival-promoting factor did not further affect protein or neurotransmitter synthesis. Thus, the serum fraction does not contain significant amounts of the macromolecules that underlie the trophic activity of the tissue extracts and conditioned media. Serum-free conditioned media and muscle extracts, as prepared here, do not support long-term spinal cord neuronal survival in vitro (Kaufman and Barrett, 1983). Thus, these preparations do not contain appreciable levels of the neuronal survival-promoting factor. Although the molecular weight of the serum fraction $(55,000$; Kaufman and Barrett, 1983) is close to the molecular weight of the active tissue-derived fraction $(40,000)$, their different biological effects indicate that they contain distinctly different factors with little cross-contamination.

The observation that muscle extract prepared from newborn rats caused an increase in CAT activity without significantly affecting GABA synthesis (Fig. 4) suggests that the macromolecule(s) that stimulates cholinergic development is distinct from that decreasing GABA synthesis.

Our experimental procedures could not dissociate enhancement of CAT activity from enhancement of overall protein synthesis, consistent with the possibility that a single trophic factor might influence both these parameters. However, the dilution $(25 \mu \mathrm{g}$ of protein $/ \mathrm{ml})$ of the active $M_{\mathrm{r}}=40,000$ fraction of MCM increased protein synthesis 3-fold without significantly increasing CAT activity (Fig. 3), suggesting either dif- 
fering sensitivities to the same agent or the existence of two distinct factors. Nishi and Berg (1981) have reported the separability of tissue extract macromolecules that enhance growth and CAT activity in cultures of ciliary ganglion neurons, and the results of Smith and Appel (1983) and Smith et al. (1983) suggest that muscle produces analogous growth and cholinergic-enhancing factors active on spinal cord neurons.

In conclusion, several different tissue-derived macromolecules influence rat spinal cord neurons in culture. These include an $M_{\mathrm{r}}=40,000$ factor(s) from conditioned media and muscle extracts that enhances ACh synthesis, CAT activity, and protein synthesis, and an $M_{\mathrm{r}}=40,000$ factor(s) in conditioned media that depresses GABA synthesis. These conditioned medium and muscle extract macromolecules are distinct from a serum factor that supports neuronal survival (Kaufman and Barrett, 1983).

\section{References}

Berg, D. K. (1978) Acetylcholine synthesis by chick spinal cord neurons in dissociated cell culture. Dev. Biol. 66: 500-512.

Bradford, M. (1976) A rapid and sensitive method for the quantitation of microgram quantities of protein utilizing the principle of proteindye binding. Anal. Biochem. 72: 248-254.

Collins, F. (1978) Induction of neurite outgrowth by a conditioned medium factor bound to the culture substratum. Proc. Natl. Acad. Sci. U. S. A. 75: 5210-5213.

Czeh, G., R. Gallego, N. Kudo, and M. Kuno (1978) Evidence for the maintenance of motoneurone properties by muscle activity. J. Physiol (Lond.) 281: 239-252.

Dribin, L. B., and J. N. Barrett (1980) Conditioned medium enhances neuritic outgrowth from rat spinal cord explants. Dev. Biol. 74: 184195.

Dribin, L. B., and J. N. Barrett (1982) Two components of conditioned medium increase neuritic outgrowth from rat spinal cord explants. J. Neurosci. Res. 8; 271-280.

Fonnum, F. (1975) A rapid radiochemical method for the determination of choline acetyltransferase. J. Neurochem. 24: 407-409.

Giller, E. L., Jr., J. H. Neale, P. N. Bullock, B. K. Schrier, and P. G. Nelson (1977) Choline acetyltransferase activity of spinal cord cell cultures increased by coculture with muscle and by muscle-conditioned medium. J. Cell Biol. 74: 16-29.

Godfrey, E. W., B. K. Schrier, and P. G. Nelson (1980) Source and target cell specificities of a conditioned medium factor that increases choline acetyltransferase activity in cultured spinal cord cells. Dev. Biol. 77: 403-418.

Hamburger, V. (1934) The effects of wing bud extirpation on the development of the central nervous system in chick embryos. J. Exp. Zool. 68: 449-494.

Henderson, C. E., M. Huchet, and J. P. Changeux (1981) Neurite outgrowth from embryonic chicken spinal neurons is promoted by media conditioned by muscle cells. Proc. Natl. Acad. Sci. U. S. A. 78: 2625-2629.

Hildebrand, J. G., D. L. Barker, E. Herbert, and E. A. Kravitz (1971) Screening for neurotransmitters: A rapid radiochemical procedure. J. Neurobiol. 2: 231-246.

Kaufman, L. M., and J. N. Barrett (1983) Serum factor supporting the long-term survival of rat spinal cord neurons in culture. Science 220 : $1394-1396$.

Lander, A. D., D. K. Fujii, D. Gospodarowicz, and L. F. Reichardt (1982) Characterization of a factor that promotes neurite outgrowth: Evidence linking activity to a heparan sulfate proteoglycan. J. Cell Biol. 94: 574-585.

Le Douarin, N. M. (1981) Plasticity in the development of the peripheral nervous system. Ciba Found. Symp. 83: 19-50.

Longo, F. M., M. Manthorpe, and S. Varon (1982) Spinal cord neuronotrophic factors (SCNTFs). I. Bioassay of schwannoma and other conditioned medium. Dev. Brain Res. 3: 277-294.

Nishi, R., and D. K. Berg (1981) Two components from eye tissue that differentially stimulate the growth and development of ciliary ganglion neurons in cell culture. J. Neurosci. 1: 505-513.

Nurcombe, V., M. A. Hill, K. L. Eagleson, and M. R. Bennett (1984) Motor neuron survival and neuritic extension from spinal cord explants induced by factors released from denervated muscle. Brain Res. 291: 19-28.

Patterson, P. H., and L. L. Y. Chun (1977a) The induction of acetylcholine synthesis in primary cultures of dissociated rat sympathetic neurons. I. Effects of conditioned medium. Dev. Biol. 56: 263-280.

Patterson, P. H., and L. L. Y. Chun (1977b) The induction of acetylcholine synthesis in primary cultures of dissociated rat sympathetic neurons. II. Developmental aspects. Dev. Biol. 60: 473-481.

Patterson, P. H., L. F. Reichardt, and L. L. Y. Chun (1975) Biochemical studies on the development of primary sympathetic neurons in cell culture. Cold Spring Harbor Symp. Quant. Biol. 40:389-397.

Reichardt, L. F., and P. H. Patterson (1977) Neurotransmitter synthesis and uptake by isolated sympathetic neurons in microcultures. Nature 270: 147151.

Smith, R. G., and S. H. Appel (1983) Extracts of skeletal muscle increase neurite outgrowth and cholinergic activity of fetal rat spinal motor neurons. Science 219: 1079-1080.

Smith, R. G., J. McManaman, and S. H. Appel (1983) Evidence for biochemical separation of morphologic and cholinergic-active trophic factors from extracts of newborn rat skeletal muscle. Soc. Neurosci. Abstr. 9: 616.

Tanaka, H., M. Sakai, and K. Obata (1982) Effects of serum, tissue extract, conditioned medium, and culture substrata on neurite appearance from spinal cord explants of chick embryo. Dev. Brain Res. 4: $303-312$.

Vaca, K., and S. H. Smith (1981) Cell culture of dissociated rat spinal cord as an assay system for trophic and toxic substances. Soc. Neurosci. Abstr. 7: 693 .

White, H. L., and C. J. Cavallito (1970) Inhibition of bacterial and mammalian choline acetyltransferases by styrylpyridine analogues. J. Neurochem. 17: 1579-1589.

Wroblewski, F., and J. S. LaDue (1955) Lactic dehydrogenase activity in blood. Proc. Soc. Exp. Biol. Med. 90: 210-213. 